(3) Lattice imperfection of the ground product increased with increasing specific surface area.

\section{References}

1) Kubo, T.: 'Introduction to Mechano-chemistry', Tokyo Kagaku Dojin Co., Ltd. (1978).
2) Timoshenko and Goodier: 'Theory of Elasticity', McGraw Hill (1934).

3) Lawn, B.R. and T.R. Wilsaw: 'Fracture of Brittle Solid', Cambridge Univ. Press (1975).

4) Bowden, F.P. and D. Tayber: 'Friction and Lubrication of Solid Part II', Clarendon Press, Oxford (1954).

\title{
Explanation of the cover photograph
}

The cover photograph (by TEM) shows a very fine talc powder with the magnitude of $10000 \mathrm{X}$. The powder was obsystem developed by Hosokawa Micromeritics Laboratory. The particle size distributions of the raw material (average diameter: $50 \mu \mathrm{m}$ ) and the ground product (average diameter: $0.5 \mu \mathrm{m}$ ) are indicated in the right figure. The BET adsorption method provided the specific surface area of $43.8 \mathrm{~m}^{2} / \mathrm{g}$. tained through dry grinding with UMF

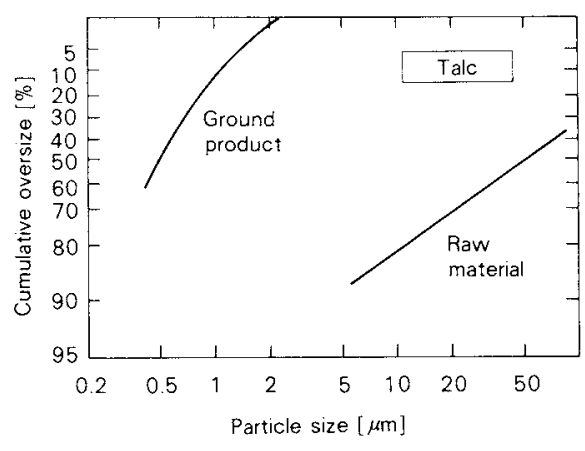

